\title{
Partial Oxidation of JP8 in a Well-Insulated
}

\section{Distributed Reactor}

\author{
Richard Scenna ${ }^{a, b}$ Ashwani K. Gupta ${ }^{a, *}$ \\ ${ }^{a}$ Department of Mechanical Engineering, University of Maryland, \\ ${ }^{\mathrm{a}, \mathrm{b}}$ US Army Research, Development and Engineering Command, \\ CERDEC, CPI \\ *Corresponding author, E-mail: akgupta@,umd.edu
}

\section{Abstract}

10 Low temperature fuel reforming via partial oxidation in a distributed reactor has shown superior performances compared to other lower temperature approaches. Previous results and literature indicated higher reactor temperatures to yield superior results. The well-insulated reactor developed incorporated elements of the low temperature reactor

15 design. The syngas obtained was of better quality in terms of gas species component present and the syngas heating value than that reported previously from a non-catalytic reformer. The syngas composition consisted of $19.2 \%$ hydrogen and $20.8 \%$ carbon monoxide and these values are higher than the previously reported data. Lower series of

20 hydrocarbons (acetylene and propane) were only detected in trace amounts (less than $15 \mathrm{ppm}$ ). Elevated reactor temperatures promoted the dissociation of lower series of hydrocarbons (methane, acetylene, and 
ethylene), which provided additional syngas formation. The gas species concentrations obtained approached that of catalytic reforming. Flame regime was determined through numerical diagnostics. As reaction regime became less distributed with higher injection temperature,

5 reformate quality was adversely impacted. The mitigation of thermal losses from the well-insulated reactor promoted superior reformer efficiency by allowing the reactor to achieve conditions not possible in low temperature reactors.

\subsection{Introduction}

Reforming is the chemical decomposition of hydrocarbon fuels into syngas (primarily hydrogen and carbon monoxide). Syngas produced can be directly utilized in a fuel cell or other applications. Fuel cells are attractive as they provide enhanced efficiency for mobile power applications over conventional internal combustion engines. The fuel

15 cells use hydrogen as the input fuel. However, hydrogen is not naturally available and is challenging to store. Reforming allows for hydrogen to be produced and utilized when and where it is needed. Currently, approximately $95 \%$ of all hydrogen is derived from steam reforming of natural gas[1]. Liquid hydrocarbon fuels have higher volumetric energy

20 density than either liquid or compressed hydrogen. Therefore, the use of liquid fuels to produce hydrogen is of significant interest in many power and propulsion applications. 
Logistically it is more desirable to reform hydrocarbon fuels, than utilizing liquid or compressed hydrogen. In addition, certain users such as the United States Army are logistically restricted to a mandatory fuel. The United States Army is required to use Jet Propellant 8 (JP8), which

5 can have concentrations of sulfur up to $3000 \mathrm{ppm}$. Sulfur concentrations of this magnitude will damage most reforming catalyst. A non-catalytic approach is more suitable and was selected as it is unaffected by the sulfur present in the fuel. In a system, a gaseous phase desulfurizer will be required, but this is a more mature technology than liquid phase 10 desulfurization.

Fuel cells have different requirements of syngas composition. A proton exchange membrane (PEM) fuel cell requires high purity hydrogen (99.999\%) but trace amounts of carbon monoxide will poison the fuel cell. A high temperature PEM fuel cell is more tolerant of carbon

15 monoxide, and is able to tolerate $4-5 \%$ carbon monoxide prior to irreversible damage. A PEM or high temperature PEM will employ a water gas shift (WGS) reactor to reduce carbon monoxide concentration and increase hydrogen content in the syngas. A solid oxide fuel cell can utilize hydrogen, carbon monoxide, and can internally reform methane.

20 Non-catalytic reformers typically produce syngas that is composed of higher concentrations of carbon monoxide and methane than catalytic reformation, which makes this reformer better suited for solid oxide fuel cell. 
Previous non-catalytic reformer designs typically react in either porous media or in a heat exchanger. These approaches have yielded positive results, but each has its own prospective drawbacks. A porous media reduces volume of the reactor and a number of authors have cited

5 damage to the ceramic foam [2-4]. In addition, Chen et al [5] found that material properties in heat exchanger based designs limit reactor conditions to less favorable temperatures than in porous media based reformers.

Fuel reforming in a distributed reactor can avoid these issues.

10 Distributed reaction regime offers the ability to achieve stable reactions without the need for ceramic foam or heat exchanger. Reactor construction is simpler, as internal entrainment stabilizes the flame. This approach allows high temperature insulation to cover a simple pressure vessel constructed of stainless steel for enhanced durability and 15 robustness.

In addition, the distributed reaction regime can enhance conversion of undesirable hydrocarbons[6]. Acetylene concentrations under distributed reaction regime were $75 \%$ lower than that under conventional flame reforming condition. The distributed reaction regime

20 suppresses soot formation in the reactor in both combustion and reformation conditions. Soot formation downstream of the reactor was unaffected by distributed reaction regime. Hartman[7] indicated optimum reforming condition occur at $1000^{\circ} \mathrm{C}$ or greater which were not 
achieved in previous low temperature work. Data reveals that reactor operation at higher temperatures would yield higher quality reformate, so that distributed reactor performance is expected to be superior at higher reactor temperatures. In this paper, partial oxidation of JP8 under a high

5 temperature distributed reaction regime is explored and quantified.

\subsection{Experimental Facility}

\subsection{Reactor}

The reactor was comprised of a stainless steel pressure vessel (SS304) having internal volume of $0.926 \mathrm{~L}$. High purity alumina

10 insulation mixed with alumina binder coated the interior of the reactor. The insulated liner was $2.54 \mathrm{~cm}$ thick along inner walls of the chamber. The top and base of the reactor had $5.08 \mathrm{~cm}$ thick insulation, see Fig. 1 . A high purity alumina (97\%) is resistant to reduction by the syngas. Alumina is a common insulation in reformers and in catalyst support. In

15 both applications, the alumina was unreactive. However, previous work on distributed combustor has used shock resistant silica bonded insulation[8]. Literature has shown shock resistant silica based binders to be easily damaged in reducing environment[9].

The reactor was enlarged by $5.08 \mathrm{~cm}$ over the previous design in

20 order to increase minimum residence times of gases in the reactor to 380 $\mathrm{ms}[6]$. The reactor was wrapped with heat tape and a secondary layer of $5.08 \mathrm{~cm}$ thick insulation. The heating tape allowed preheating the reactor to foster a faster startup. It also served to reduce thermal stress on the 
insulation material. The heat tape was deactivated after ignition. A spark igniter located directly opposite to the central injector ignited the mixture in the reactor.

A premixed fuel-air mixture was injected into the reactor through

5 a central location, having an inner diameter of $3.86 \mathrm{~mm}$. Prior to its injection, the temperature of premixed fuel-air mixture was measured. Reynold number in the nozzle was determined to be in the range of 3674 to 4190 , which corresponds to an average residence time of 900 and 660 ms, respectively. Reformate was exhausted through two outlets on either

10 side of the injector, located $3.02 \mathrm{~cm}$ apart. The outlets had an inner diameter of $5.59 \mathrm{~mm}$. Dual outlets reduced the chances of any catastrophic failure in case of unwanted blockage in one of the outlets.

\subsection{Test Bed}

The test bed construction was similar in design to the previous

15 work[6], but with modifications. Figure 2 shows a schematic of the test bed. Fuel and air were individually heated, prior to mixing in a four element static mixer. The mixer was enlarged compared to the previous work[6] to handle potential for steam vaporizer (not shown). Per manufacture, mixing efficiency was greater than $99.99 \%$ under the

20 experimental conditions. Reformate from the two outlets of the reactor was ducted to a common exhaust. In addition, a liquid /vapor separator prevents unreacted fuel from escaping the test bed during ignition. 
Jet Propellant 8 (JP8) used in the experiment had a heating value of $42.8 \mathrm{MJ} / \mathrm{kg}$, and carbon content of $86.33 \%$ (mass). Sulfur concentrations were found to be approximately 150-160ppm. JP8 chemical composition on volume bases typically consists of $50-65 \%$ iso

5 and normal alkanes, 10-20\% cyclo-alkanes, 15-20\% mono-aromatics, and $1-3 \%$ poly-aromatics hydrocarbons.

\subsection{Instrumentation}

Reformate concentrations were measured using an online four channel micro gas chromatograph. The gas chromatograph was capable

10 of detecting fixed gases and lower hydrocarbons of up to C5 with an accuracy of $1.17 \%$ of reading. The gas chromatograph was calibrated against three primary standards with an analytical tolerance of $0.17 \%$ of

measurement. The gas chromatograph sampled the exhaust stream every 3.2 minutes. Prior to the gas chromatograph, water vapor was removed

15 with a condenser to prevent any damage to columns in the micro gas chromatograph. Carbon balance indicated 80\%-93\% detection based on the input fuel composition. Lower carbon balance corresponded with higher injection temperature. The undetected carbon was attributed to the observed soot formation in the exit stream. using $\mathrm{K}$ type thermocouples that were capable of withstanding to $1325^{\circ} \mathrm{C}$. A thermocouple was placed in the center of the reactor, located between the center outer steel pressure vessel and secondary insulation. 
Two thermocouples where placed $12.7 \mathrm{~cm}$ downstream of the exhaust.

Exhaust thermocouples were not a direct indicator of reactor temperature, but monitored for potential blockages. A thermocouple monitored the internal reactor temperatures. The thermocouple was

5 positioned flush to the inner surface of the reactor to avoid flow obstruction. However, during ignition reactor temperatures exceeded thermocouple temperature of $1325^{\circ} \mathrm{C}$.

\subsection{Results and Discussion}

\subsection{Reactor Modes}

The reactor showed two distinct operating modes during startup, which were determined from reformate composition and the reactor temperature profile. After ignition, for a period of 35 to 50 minutes, the reactor demonstrated unstable reformate concentrations and temperatures. This will be referred to as the first mode. After this time,

15 reformate concentrations and temperature stabilized. This period will be referred to as second mode of operation.

During start up the reactor was operated at $\mathrm{O} / \mathrm{C}=1.25$; excess oxygen reduces blockages and shortens the time to transition to the second mode. The primary work was chosen at $\mathrm{O} / \mathrm{C}=1.0$ due to the ideal

20 reforming conditions (sufficient reactants with no excess oxygen). The reactor was operated at $4.1 \mathrm{~kW}_{\text {th }}$ with an oxygen/carbon $(\mathrm{O} / \mathrm{C})$ ratio of 1.25 at start-up. The feed stream was injected at $515^{\circ} \mathrm{C}$. The fuel, preheated to $300^{\circ} \mathrm{C}$, was injected at a flow rate of $5.79 \mathrm{~g} / \mathrm{min}$ that allowed 
complete fuel vaporization. Air, preheated to $600^{\circ} \mathrm{C}$, was injected at $35.5 \mathrm{~g} / \mathrm{min}$.

On startup the reactor underwent a transitional mode until the reactor stabilized, characterized by poor quality reformate. In this mode,

5 the thermocouples located at the injector and exit gas stream showed elevated temperatures, while outer wall thermocouple showed decrease in temperature relative to the second mode, see Fig 3. Elevated injection temperatures were conjectured to be the result of heat conducted back through the nozzle. This indicates that the reaction zone occurs primarily

10 at the front of the reactor. In addition, reformate quality was considerably reduced as compared to the later mode. The results shown in figure 4 shows reduced hydrogen and carbon monoxide concentrations, and elevated acetylene concentrations. The high acetylene concentrations, a known soot precursor, corresponded with

15 visible smoke emission from the exit pipe.

Possible cause of the instability in the reactor were conjectured to be from the lack of thermal mass inside the reactor and the resulting need for the reactor to transition to thermochemical equilibrium. The lack of symmetry during ignition is attributed to hydrocarbon formation in

20 exhaust lines. During startup, before sufficient entrainment could occur significant hydrocarbon formation occurred inside the reactor and and exhaust line. The restriction in flow that resulted from the hydrocarbon deposits is attributed to biasing the exhaust to a particular outlet, that 
contributed to lack of symmetry to cause slight differences between the two outlets. Uneven flow will result in a portion of the flow crossing the inlet, while oxidizing exhaust gases will results in elevated temperatures at front of the reactor. However, immediately after the start-up, the

5 exhaust cleared itself with time resulting in a uniform flow, temperature and gas composition.

This was not observed in the previous work[6], which may be due to the larger size of the reactor vessel. Increased reactor size exacerbated this issue.

10 The flow and chemical reactions in the reactor stabilized after a period of approximately 20 minutes. The reaction zone detached from front of the reactor and distributed throughout the reactor. This is conjectured from decreased injection and exhaust gases temperatures, and a corresponding increase in wall temperatures, see Fig. 3. In

15 addition, exhaust temperatures between the two outlets appear to equalize indicating equal flow through both the outlets. Figure 4 shows complete stabilization to occur after a period of 50 minutes. Hydrogen and carbon monoxide concentrations showed an upward trend with a corresponding decrease in hydrocarbons. Acetylene concentrations

20 dropped below the detection level of $10 \mathrm{ppm}$. The drop in acetylene concentrations, a known soot precursor, corresponded with visible disappearance of smoke emission from the exit pipe.

\subsection{Injection Temperature}


The reactor was operated at $5.1 \mathrm{~kW}_{\mathrm{th}}$, at a fixed oxygen to carbon ratio of unity. Fuel and air were operated at fixed flow rates of 7.08 $\mathrm{g} / \mathrm{min}$ and $35.5 \mathrm{~g} / \mathrm{min}$, respectively. Air preheats were used to control the injection temperature. Injection temperatures, measured prior to injection

5 into the reactor, ranged from 383 to $556^{\circ} \mathrm{C}$. Fuel was vaporized at constant $300^{\circ} \mathrm{C}$. To prevent fuel condensation after vaporizer, lower injection temperatures were limited to $383^{\circ} \mathrm{C}$. The reactor stability was determined from the observed reactor temperatures and reformate's concentration.

\section{$10 \quad$ 3.2.1 Flame Regimes}

The flame regime was determined through numerical simulations, as the reaction zone was unobservable. Previous work has shown strong capability of predicating the emergence of distributed reaction regime[10], with a comparable design. Under condition tested shown in

15 figure 5, reactions only occurred under the distributed reaction regime. Numerical simulation indicated that increasing injection temperatures resulted in a less distributed reactor, as experimental conditions transitioned away from distributed reaction regime. Increased injection temperatures fostered conditions that accelerated laminar flame speed

20 and shortened laminar flame length.

A borghi diagram presented in figure 5 , demonstrates the relevant flame regimes against Damkohler number(Da) and Turbulent Reynolds number $\left(R e_{o}\right)$, see eq. 1 and eq. 2 . The Damkohler number(Da) represent 
the ratio between the characteristic mixing time scale to characteristic chemical time scale. Turbulent Reynolds $\left(R e_{o}\right)$ is based on integral length scale $\left(l_{o}\right)$ as given by Glassman[11] and Law[12], see eq. 2. Flame regime is defined as the ratio between the laminar flame thickness $(\delta)$,

5 integral length $\operatorname{scale}\left(l_{o}\right)$, and kolmogorov length scale $\left(l_{k}\right)$. Distributed flame regime occurs at Da less than one and when $\delta$ exceeds $l_{o}$ [13]. The upper limit of the distributed reaction regime, known as damkohler criterion, occurs when $\delta$ equals $l_{o}$. Conditions that exceed damkohler criterion are associated with the flamelets in eddies and wrinkled flames

10 regimes. Flamelets in eddies regime occurs when $\delta$ is less than $l_{o}$, but greater than $l_{k}$. The wrinkled flame regime occurs at Da greater than one and when $\delta$ is less than $l_{k}$.

Integral length $\operatorname{scale}\left(l_{o}\right)$, kolmogorov length scale $\left(l_{k}\right)$, and turbulence velocity $\left(u^{\prime}\right)$ are functions of the volume averaged turbulent

15 kinetic energy $(k)$ and turbulent energy dissipation $(\varepsilon)$. These properties were directly calculated using a commercial CFD code (Fluent), see eq. 3-5. Kinematic viscosity $(v)$ is a function of working fluid properties. The integral scales were found to be relatively constant $(1.90 \mathrm{~mm})$, while the kolmogorov length scales were found to range between 0.44 -

$200.49 \mathrm{~mm}$. Turbulent velocity was found to be between $1.29-1.62 \mathrm{~m} / \mathrm{sec}$.

$$
\begin{aligned}
& D a=\frac{\left(\frac{l_{o}}{u}\right)}{\left(\frac{\delta}{s_{l}}\right)} \\
& R e_{O}=\frac{u^{\prime} l_{o}}{v}=\frac{u^{\prime} l_{o}}{S_{l} \delta}
\end{aligned}
$$




$$
\begin{aligned}
& u^{\prime}=\left(\frac{2}{3} k\right)^{1 / 2} \\
& l_{o}=\frac{\left(\frac{2}{3} k\right)^{3 / 4}}{\varepsilon} \\
& l_{k}=\left(\frac{v^{3}}{\varepsilon}\right)^{\frac{1}{4}}
\end{aligned}
$$

Numerical simulations converged until the residual values were bellow 10E-5. Arghode [14] found that the k- $\varepsilon$ realizable viscous model would give strong agreement with experimental data. Second order solutions were employed to give increased accuracy. Reactor symmetry allowed simulation of a quarter of the reactor, which reduced the mesh size to $511 \mathrm{k}$ element.

10 Laminar flame speed was determined using Chemkin Pro[15]. This code was used to estimate laminar flame thickness $(\delta)$ through the ratio of thermal diffusivity $(\alpha)$ to laminar flame speed $\left(S_{l}\right)$, see eq. 6. A reduced kinetic mechanism was used along with a surrogate that was designed to predict the laminar flame speed[16]. This approach has been

15 found to strongly predict reaction regime and the development of a distributed reaction regime[10]. A five component surrogate was used which has been previously shown to predict flame speed with high accuracy[17]. Laminar flame speed was found to be 9.9 to $22.5 \mathrm{~cm} / \mathrm{sec}$, while laminar flame thickness ranged between 2.02-4.12 $\mathrm{mm}$.

$$
\delta=\frac{2 \alpha}{S_{l}}
$$




\subsubsection{Reformate Concentrations}

Injection temperatures were found to alter the reaction regime, which influenced reformate quality. As the reactor became less distributed, due to an increase in injection temperatures, hydrogen and

5 carbon monoxide concentrations were adversely affected, see Fig. 6. A less distributed reactor promoted hydrocarbon formation, see Fig. 7. Reformate composition changed rapidly as experimental conditions approached the damkohler criterion. However, carbon dioxide concentrations were not strongly influenced by injection temperatures or

10 reaction regimes. The high concentration of carbon monoxide and low concentrations of carbon dioxide indicated complete mixing to occur. Hartmen et al[7] have cited that optimum temperature for reforming of middle distillate fuel lies in the range of $1000-1100^{\circ} \mathrm{C}$. Previous low temperature work indicated that under distributed reaction

15 regime higher injection temperatures improved hydrogen content[6]. In that work, reactor conditions occurred at lower than optimum temperatures. As injection temperatures increased, reactor conditions occurred closer to optimum temperatures. This offset the negative impact of a less distributed reactor. In the current work, the reactor conditions

20 were at or near the optimum temperatures. As injection temperatures rose, the negative effects of the reactor transitioning away from distributed reaction regime became more apparent. 
Typically catalytic partial oxidation of JP8 yield concentrations have been reported to be $24 \%$ hydrogen and $24 \%$ carbon monoxide[18]. Syngas composition shown here approached that of catalytic reforming, consisting of $19.2 \pm 0.22 \%$ hydrogen and $20.8 \pm 0.35 \%$ carbon monoxide.

5 The non-catalytic literature[19] of a jet fuel shows hydrogen of and carbon monoxide concentrations of $14 \%$ and $19 \%$, respectively. Hydrogen and carbon monoxide concentrations demonstrated in this work exceeded those demonstrated in low temperature reactors[6].

Of the hydrocarbons detected, only methane was detected in

10 considerable amount. However, methane is a desirable hydrocarbon. Solid oxide fuel cells can internally reform methane, allowing direct utilization of methane by the fuel cell. Propane and acetylene were detected only in trace quantities (less than 15 ppm), see Fig. 7. Propane and acetylene concentrations were detected near the lower calibration

15 limit for the micro-GC (10ppm lower limit). In the low temperature distributed reactor [6] ethylene, ethane, and trace amounts of higher hydrocarbons(butane and hexane) were detected, but were not detected during the high temperature reactor work presented here. Literature shows that optimum reforming conditions occurred at higher reactor 20 temperatures [7]. Higher temperatures are associated with the dissociation of methane and other lower molecular weight hydrocarbons. 


\subsubsection{Reforming Efficiency}

Reforming efficiency is defined as the ratio of the lower heating value of the syngas to the lower heating value of the fuel, see Fig. 8 . Reforming efficiency is presented for both solid oxide (Eq. 7) and water

5 gas shift (WGS)/PEM fuel cell (Eq.8). Increased injection temperatures caused the reactor to become less distributed, which decreased reformate quality. Decreased reformate quality resulted in a drop in reforming efficiency.

$$
\begin{aligned}
& \frac{L H V\left(\mathrm{H}_{2}+\mathrm{CO}+\mathrm{CH}_{4}\right)}{L H V(J P 8)}=\eta_{\text {Solid } \text { Oxide }} \\
& \frac{L H V\left(\mathrm{H}_{2}+\mathrm{CO}\right)}{L H V(J P 8)}=\eta_{W G S / P E M}
\end{aligned}
$$

Previous work on distributed reaction regime at lower reactor temperatures[6] have shown reforming efficiency (Eq.7) on the order of $56-57 \%$ at comparable conditions. In this work, reforming efficiency ranged between 58-59\%. Reforming at lower temperature provided 19-

$1536 \%$ methane in the recovered energy, while it was only $1-2 \%$ of the recovered energy in current work. The higher reactor temperatures promoted the dissociation of methane, which generate higher concentrations of both hydrogen and carbon monoxide. In addition the reformate concentrations presented here are significantly better than that

20 reported in the previous non-catalytic reforming studies[2,5,6].

Reforming efficiency for catalytic partial oxidation ranged from $75 \%$ $85 \%[18]$, but are susceptible to sulfur poisoning. 


\subsubsection{Numerical Simulation}

Numerical simulation of distributed reaction regime was conducted using Chemkin Pro[15], through a series of one dimensional reactors. The reactor network consisted of adiabatic plug flow reactor

5 with a recirculation loop. The splitter recirculated fifty percent of the exhaust flow (mass basis) back to the front of the plug flow reactor. The reactor pressure was set at 12 psi. At the front of the reactor, the fuel-air stream perfectly mixed with the exhaust. This approach has the advantage of finite residence time. Figure 9 shows the reactor network as constructed from Chemkin Pro.

Numerical simulation utilized a detailed kinetic mechanism for hydrocarbons between the range of $\mathrm{C} 8$ to $\mathrm{C} 16$ under combustion, pyrolysis, and soot formation conditions. This kinetic mechanism[16] was originally intended to model combustion conditions (equivalence

15 ratios between 0.2 to 2.0 and at pressure between 0.08 to $50 \mathrm{~atm}$ ), but was shown previously to be able to adequately predict reforming with Jet A/JP8 under reforming conditions in a porous media based non-catalytic reforming[20]. The model used was comprised of 13,532 reactions and 435 species. decalin, and 20\%(vol) toluene[21]. This surrogate represents all major hydrocarbon classes found in JP8; iso and normal alkanes, cyclo-alkanes and mono-aromatic compounds. This results in an average molecular 
formula of $\mathrm{C}_{10.1} \mathrm{H}_{19.0}$ and a lower heating value of $43.06 \mathrm{~kJ} / \mathrm{kg}$. In previous work it was found that this surrogate and kinetic mechanism provided strong agreement with partial oxidation of Jet A/JP8 in a noncatalytic porous media based reformer [20,22]. However, surrogate

5 ability to predict laminar flame speed has not been verified.

Numerical simulations showed somewhat mixed agreement with the experimental data. At lower injection temperatures, the modeling was in strong agreement with the experimental data. Simulation over predicted methane formation, this could have been a result of an

10 incomplete kinetics mechanism. Steam reforming and dry reforming reactions are predicted to be active in reactor, but were not included in this mechanism. Previous work in numerical modeling of reforming also indicated this kinetic model over predicts the acetylene formation[22]. However, experimental and simulation agreement diverged with

15 increasing injection temperatures, see Figs. 10 and 11. The divergence is conjectured to be the result deviation from the initial perfectly mixed assumption.

Numerical simulation assumed fuel and air mixture would instantly mix with recirculated effluents at beginning of the reactor.

20 However, experimentally a finite amount time is required for mixing to occur. As injection temperature increased ignition occurred more rapidly, thus reducing the time for mixing. This results in the in a less thoroughly mixed reactor, which indicated a deviation from the perfectly mixed 
assumption. This may be a limitation on the numerical simulation with Chemkin Pro, but may be resolved in computational fluid dynamics (CFD). However, a sufficiently small number of chemical kinetic mechanism that could be incorporated into a CFD model to accurately

5 captured reforming behavior of JP8 is currently not available the literature. Reactions were minimized though the use of a high velocity mixer. Residence times in the mixer were estimated to be between 68ms. Temperature measurements after the mixer indicated no evidence of pre-ignition.

\section{$10 \quad 4.0$ Conclusions}

Partial oxidation of JP8 in high temperature distributed reaction regime was investigated in a well-insulated reactor, based on the original low temperature design[6]. The results presented here demonstrated the feasibility of a non-catalytic reformer ability to achieve a hydrogen rich

15 reformate using a middle distillate fuel. Numeral simulations enhanced understanding of experimental conditions and trends.

The syngas obtained was of better quality in terms of product distribution, and approached that of catalytic reforming. Syngas composition demonstrated $19.2 \pm 0.22 \%$ hydrogen and $20.8 \pm 0.35 \%$

20 carbon monoxide. Literature has shown catalytic reformate is typically composed of $24 \%$ hydrogen and $24 \%$ carbon monoxide[18]. Previous non-catalytic approaches only yielded syngas that was at most $14 \%$ hydrogen and 19\% carbon monoxide [19]. 
Higher reactor temperatures yielded higher quality reformate as compared to previous low temperature reactor[6]. Higher reactor temperatures promoted the dissociation of lower series of hydrocarbons (methane, acetylene, and ethylene), which provided additional hydrogen

5 and carbon monoxide. Mitigation of thermal losses from the insulated reactor allowed higher reactor temperatures that were not possible in the previously low temperature reactor studies[10].

The interaction of reformate product distribution to injection temperature was of significant importance. Lower injection temperatures

10 promoted conditions that favored the formation of better quality reformate. Numerical diagnostics indicated that the reaction regime became less distributed with higher injection temperatures, negatively influencing the reformate quality. Lower quality reformate negatively impacted reforming efficiency. Reformate quality changed more rapidly

15 as reaction regime approached the damkohler criterion.

The reactor showed two distinct operating modes, which were determined from reformate composition and the reactor temperature distribution. On activation, the reactor entered at a transitional mode characterized by the reaction zone shifting towards the front of the

20 reactor and poor quality reformate. After a period of 20 minutes, the flow and chemical reactions stabilized and the reactor transitioned to a more stable secondary mode. Under these conditions, the reaction zone shifted farther back into the reactor to generate improved reformate quality. 
Numerical simulations showed mixed agreement with the experimental data. At lower injection temperatures, the agreement was strong, but diverged rapidly with increase in injection temperature. The discrepancy is conjectured to be a divergence from the perfectly mixed

5 assumption. Numerical simulation assumed fuel and air mixture would instantly mix with recirculated effluent at beginning of the reactor. Experimentally as injection temperature increased, less time was available for mixing to occur, as higher temperatures fostered faster reactions. This resulted in a less thoroughly mixed reactor, which

10 indicated a deviation from the perfectly mixed assumption.

\subsection{Acknowledgments}

The authors acknowledge the support of United States Army's Research Development Engineering Command (RDECOM) Independent

15 Laboratory Innovative Research (ILIR) program and US Army Communication Electronic Research Directorate Engineering Command (CERDEC) Command Power Integration (CPI) directorate. The authors also gratefully acknowledge the help and support provided by Reaction Design for the Chemkin code used here.

\section{References}

[1] I.M. Alatiqi, G.A. Meziou, A.M. Gasmelseed, Static and dynamic simulation of steam methane reformers, Sudies Surf. Sci. Catal. 53 (1989) 535-550. 
[2] C.H. Smith, C.D. Zak, D.I. Pineda, J.L. Ellzey, Conversion of jet A to syngas by filtration combustion, in: 7th US Natl. Tech. Meet. Combust. Insitute, Alanta, 2011.

[3] H. Pedersen-Mjaanes, L. Chan, E. Mastorakos, Hydrogen production from rich combustion in porous media, Int. J. Hydrogen Energy. 30 (2005) 579-592.

doi:10.1016/j.ijhydene.2004.05.006.

[4] A. Pastore, Syngas production from heavy liquid fuel reforming in inert porous media, Cambridge, 2010.

10 https://www.repository.cam.ac.uk/handle/1810/237704 (accessed June 18, 2013).

[5] C. Chen, S. Sur, J. Thayer, H. Pearlman, P. Ronney, A noncatalytic fuel-flexible reformer, in: 8th U.S. Natl. Combust. Meet. West. State Sect., Salt Lake City, 2013: pp. 1-7.

15 [6] R. Scenna, A.K. Gupta, Partial oxidation of jp8 in a distributed reactor, J. Fuel Process. 134 (2015) 205-213. doi:http:// dx.doi.org/10.1016/j.fuproc.2015.01.036.

[7] L. Hartmann, K. Lucka, H. Köhne, Mixture preparation by cool flames for diesel-reforming technologies, J. Power Sources. 118 (2003) 286-297. doi:10.1016/S0378-7753(03)00100-9.

[8] A.E.E. Khalil, A.K. Gupta, K.M. Bryden, S.C. Lee, Mixture preparation effects on distributed combustion for gas turbine applications, J. Energy Resour. Technol. 134 (2012) 032201. doi:10.1115/1.4006481.

25 [9] P. Hamling, Effects of hydrogen gas at $1450^{\circ} \mathrm{C}$ on select fibrous alumina insulation product, (2002).

http://www.zircarceramics.com.

[10] R. Scenna, A. Gupta, Preheats effect on distributed reaction fuel reforming, in: Power Energy Convers., ASME, San Diego, 2015: pp. 1-7.

[11] I. Glassman, R.A. Yetter, Combustion, 4th ed., Academic Press, Burlington, MA, 2008. doi:10.1016/B978-0-12-088573-2.000051.

[12] Chung, Law, Combustion Physics, Cambridge University Press, Cambride, New York, 2010. 
[13] S.R. Turns, An introduction to combustion : concepts and applications, McGraw-Hill, New York, 2012.

[14] V.K. Arghode, Development of colorless distributed combustion for gas turbine applications, University of Maryland, 2011. http://onlinelibrary.wiley.com/doi/10.1002/cbdv.200490137/abstra ct (accessed June 18, 2013).

[15] Chemkin, (n.d.). http://www.reactiondesign.com.

[16] E. Ranzi, a. Frassoldati, R. Grana, A. Cuoci, T. Faravelli, a. P. Kelley, et al., Hierarchical and comparative kinetic modeling of laminar flame speeds of hydrocarbon and oxygenated fuels, Prog. Energy .... 38 (2012) 468-501. doi:10.1016/j.pecs.2012.03.004.

[17] A. Violi, S. Yan, E. Eddings, Experimental formulation and kinetic model for jp-8 surrogate mixtures, Combust. Sci. ... 174 (2002) 399-418. doi:10.1080/00102200290021740.

15 [18] T.G. Howell, Catalytic partial oxidation refoming of jp8 and s8, Air Force Institute of Technology, 2007.

[19] A. Pastore, E. Mastorakos, Syngas production from liquid fuels in a non-catalytic porous burner, Fuel. 90 (2011) 64-76. doi:10.1016/j.fuel.2010.08.003.

20 [20] R. Scenna, T. DuBois, A.K. Gupta, Chemical modeling of thermal partial oxidation of a jp8/jet a surrogate, in: 46th Army Power Sources, Orlando, 2014.

[21] T.G. DuBois, S. Nieh, Selection and performance comparison of jet fuel surrogates for autothermal reforming, Fuel. 90 (2011) 1439-1448. doi:10.1016/j.fuel.2010.12.040.

[22] R. Scenna, A.K. Gupta, Soot formation reaction effect in modeling thermal partial oxidation of jet a, in: ASME 2014 Power Conf., ASME, Baltimore, 2014: p. 5. doi:doi:10.1115/POWER2014-32252. 
Figure 1. A schematic diagram of the reactor

Figure 2. A schematic diagram of the test bed

Figure 3. Reactor temperature profile after ignition.

Figure 4. Reformate concentrations at $\mathrm{O} / \mathrm{C}=1.25$

Figure 5. Flame regime at $\mathrm{O} / \mathrm{C}=1.0$ at injection temperatures of $383-556^{\circ} \mathrm{C}$

Figure 6. Concentration of fixed gases at $\mathrm{O} / \mathrm{C}=1.0$, at injection temperatures of $383-556^{\circ} \mathrm{C}$

Figure 7. Concentration of Lower hydrogens gases at $\mathrm{O} / \mathrm{C}=1.0$, at injection temperatures of $383-556^{\circ} \mathrm{C}$

Figure 8. Reforming efficiency of solid oxide fuel cell and water gas shift/ PEM fuel cell.

Figure 9. Chemkin simulation of distributed reactor.

Figure 10. A comparison of hydrogen and carbon monoxide concentration between numerical simulations and experiments.

Figure 11. A comparison of methane and acetylene concentrations between numerical simulations and experiments. 


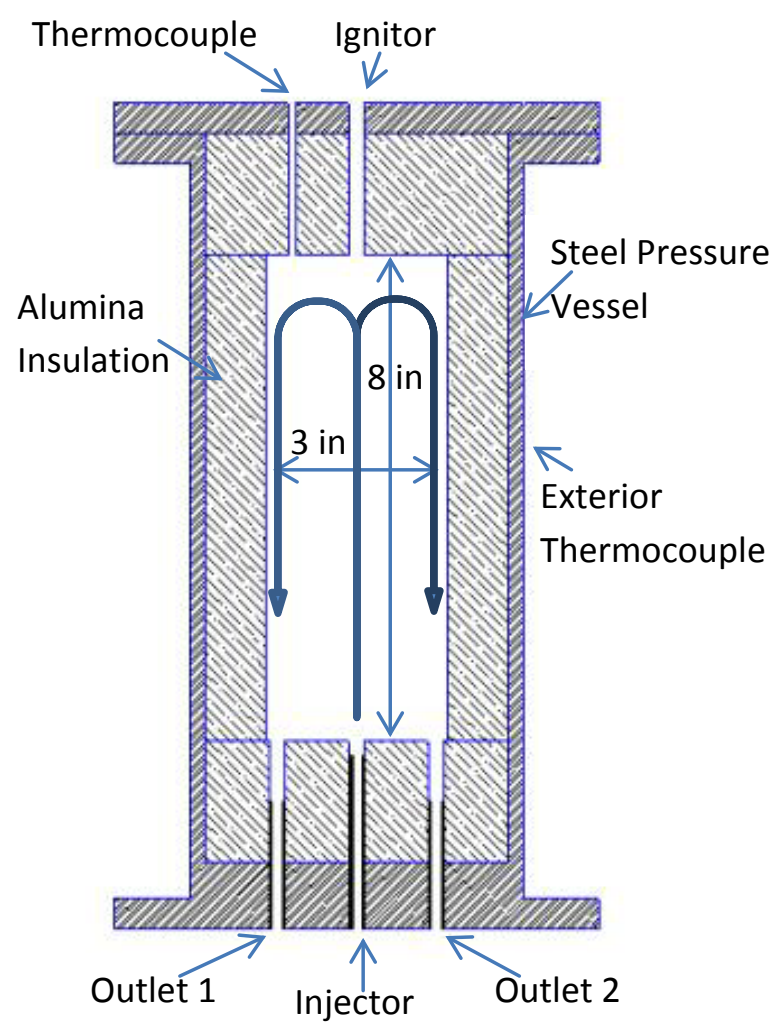


Figure 2

\section{Test Bed}

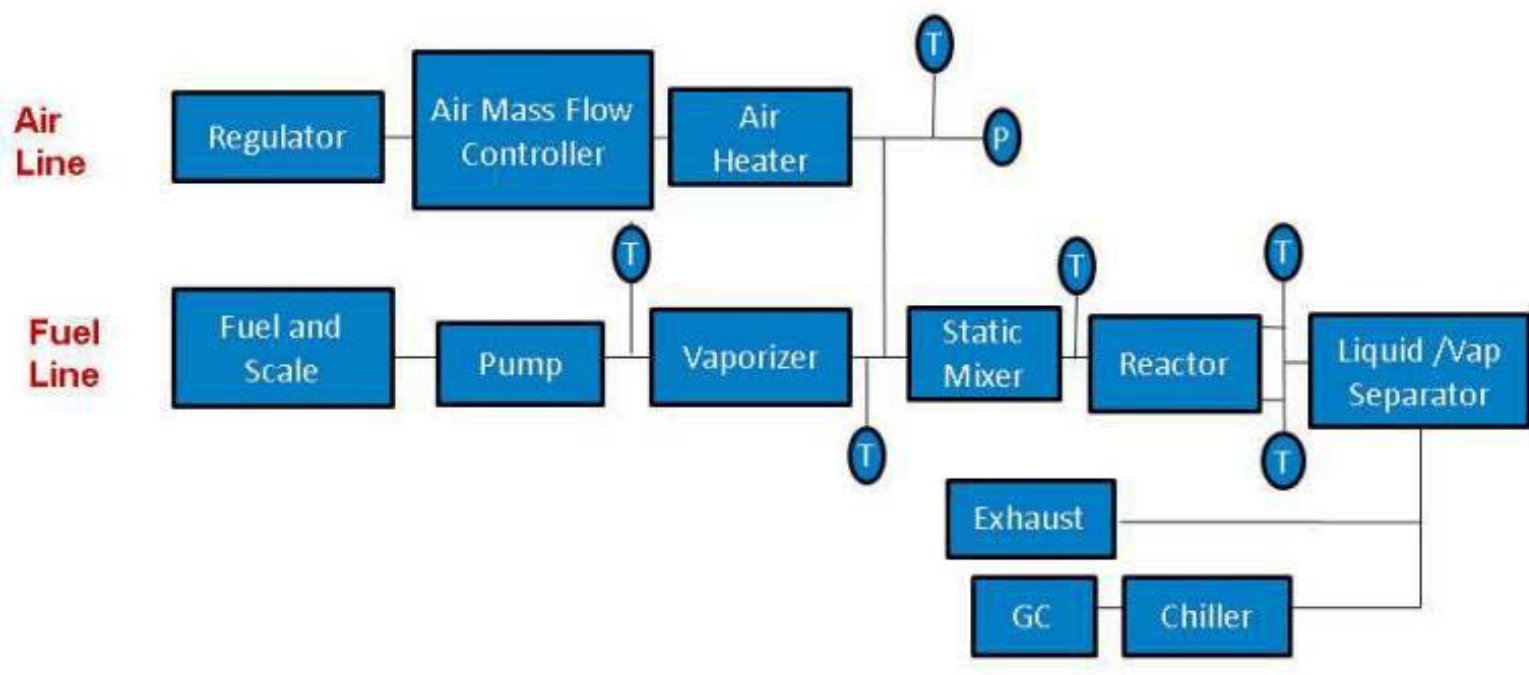

2 
Figure 3

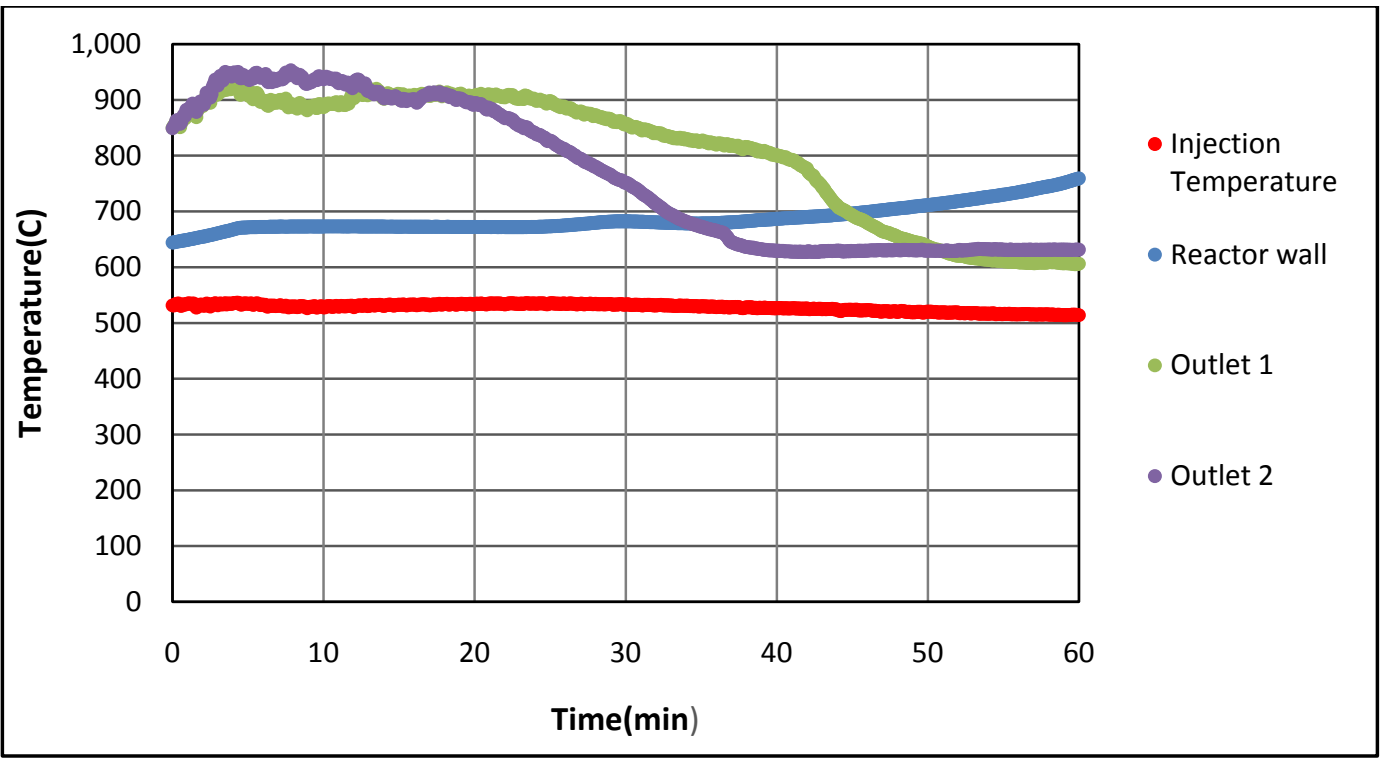


Figure 4

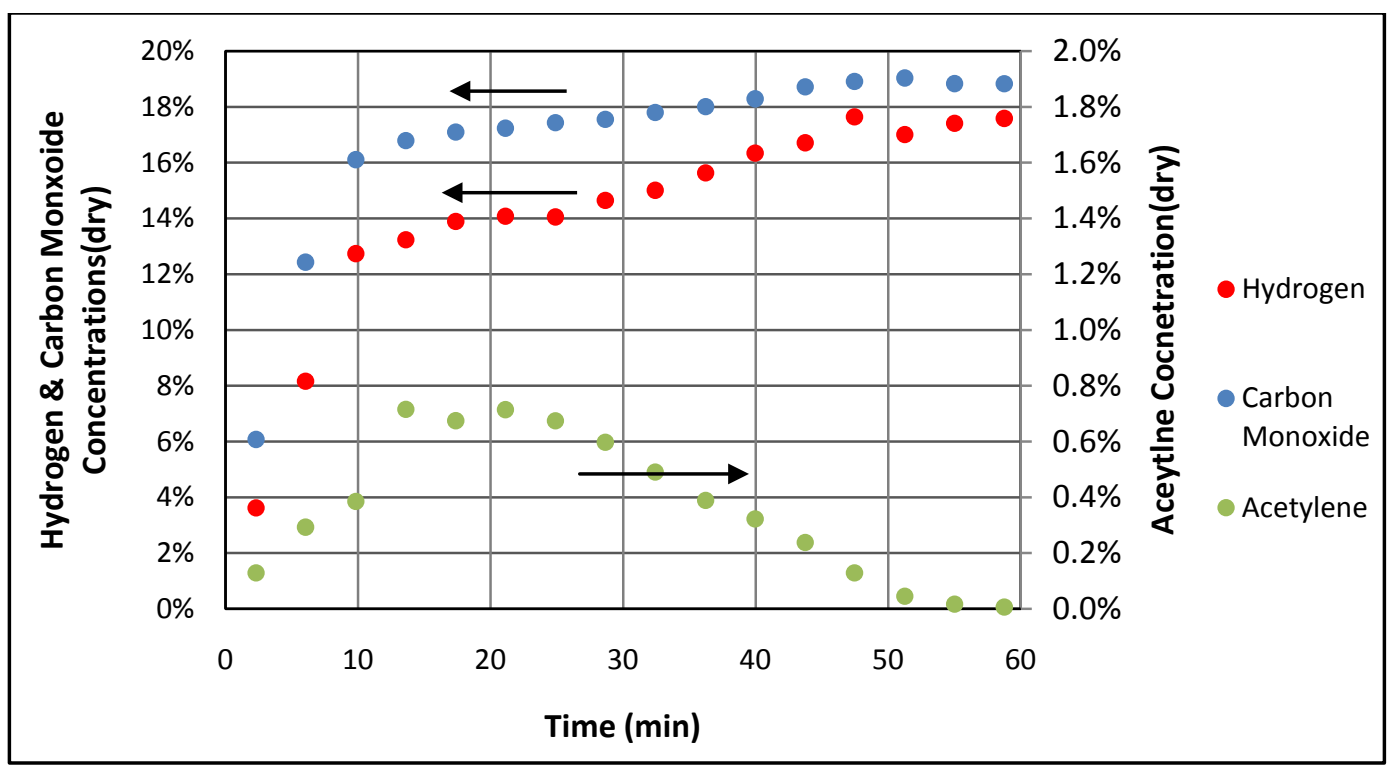


Figure 5

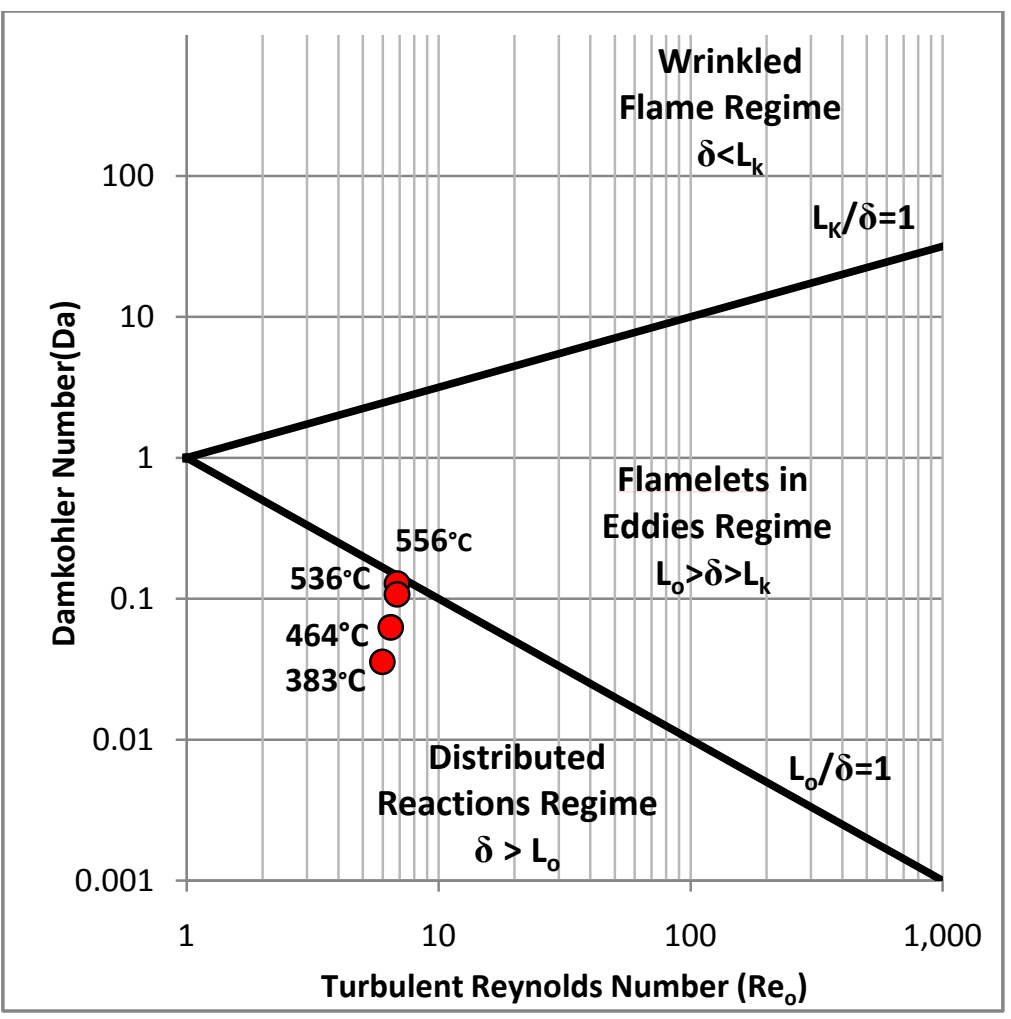


Figure 6

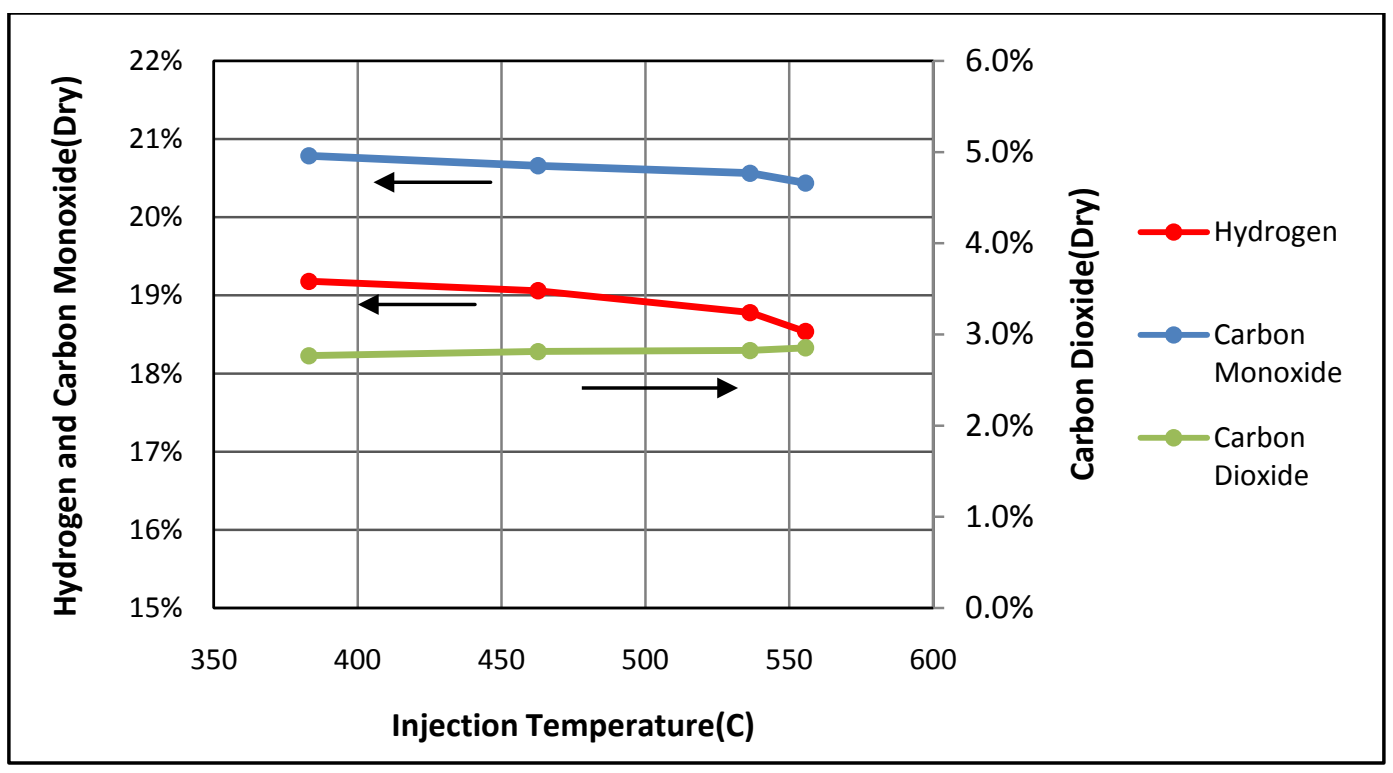




\section{Figure 7}

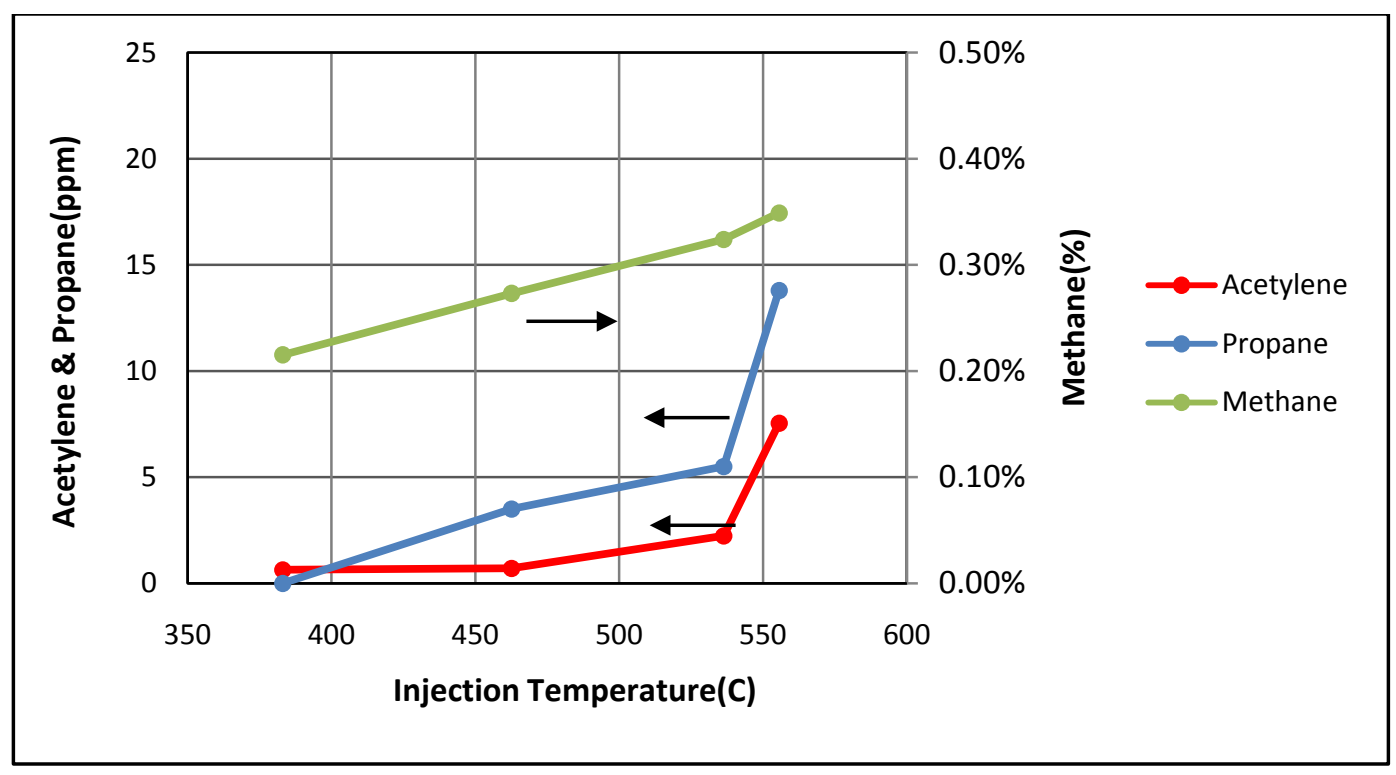


Figure 8

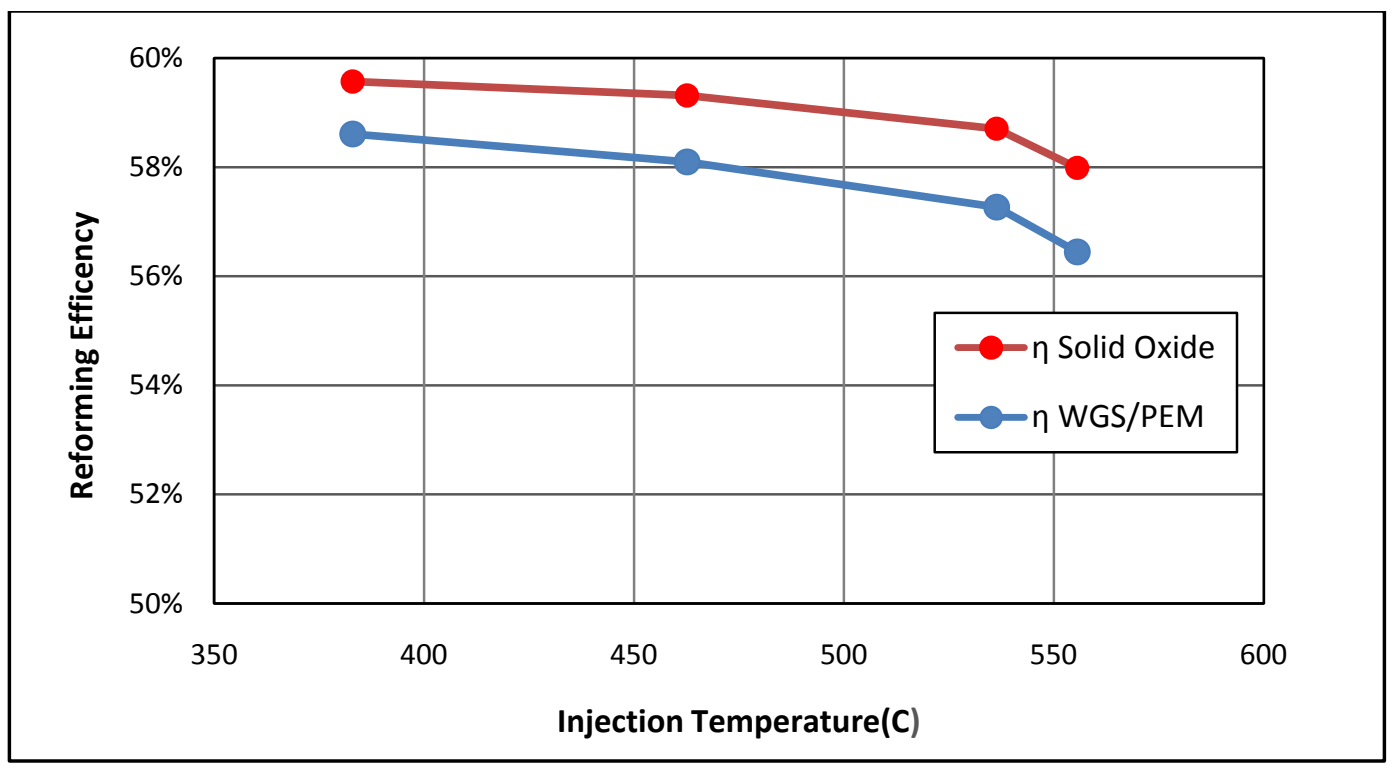


Figure 9

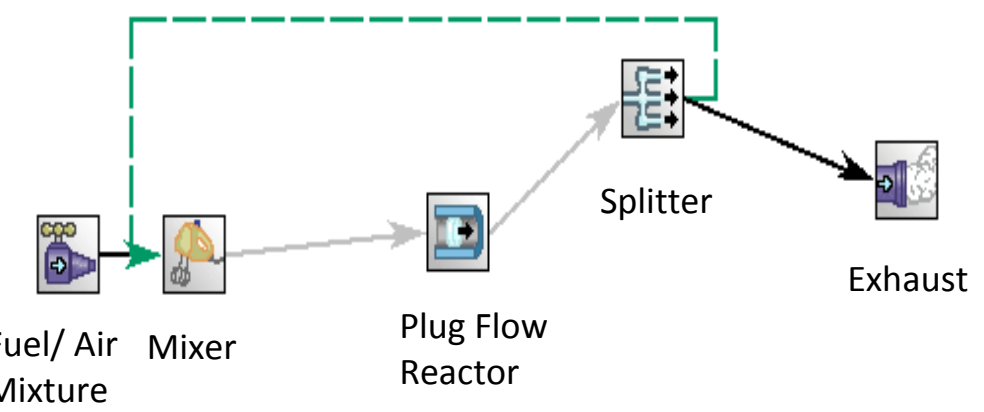




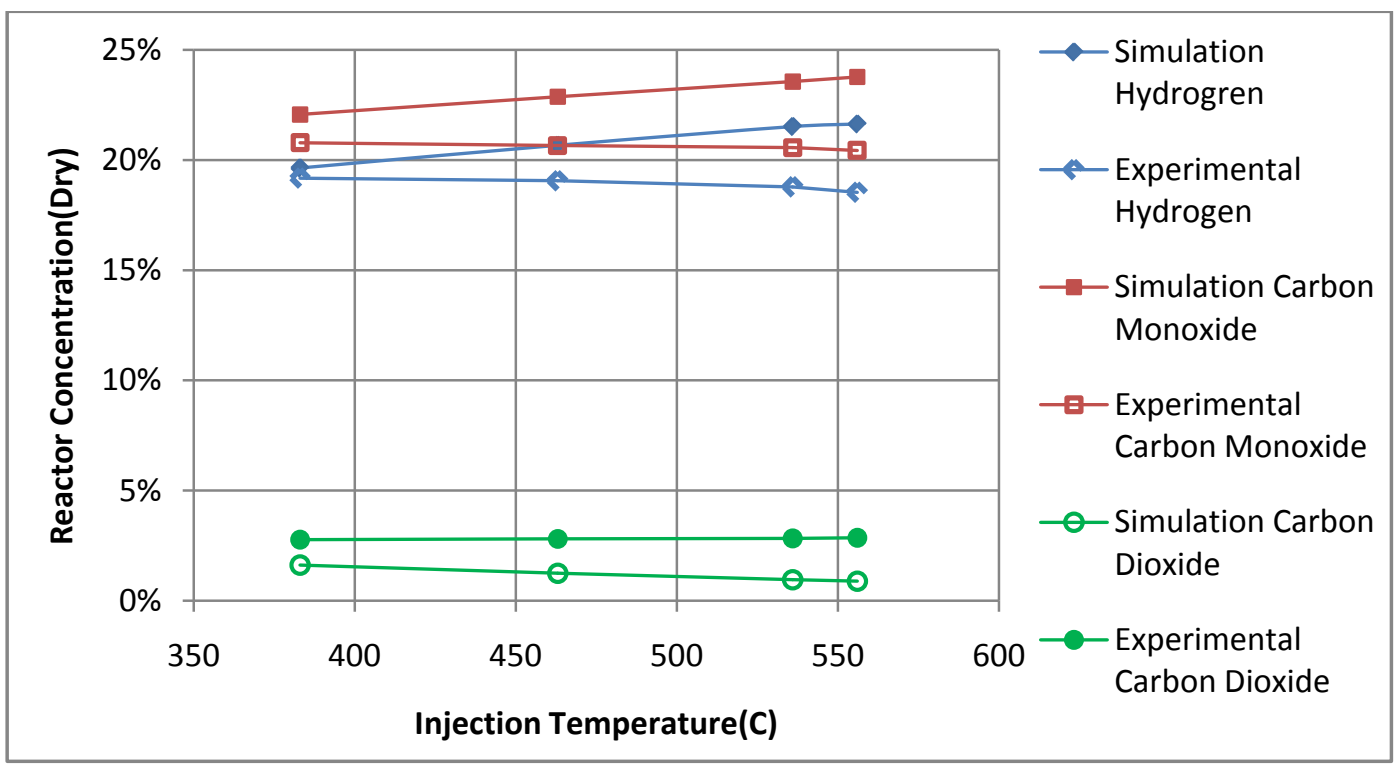




\section{Figure 11}

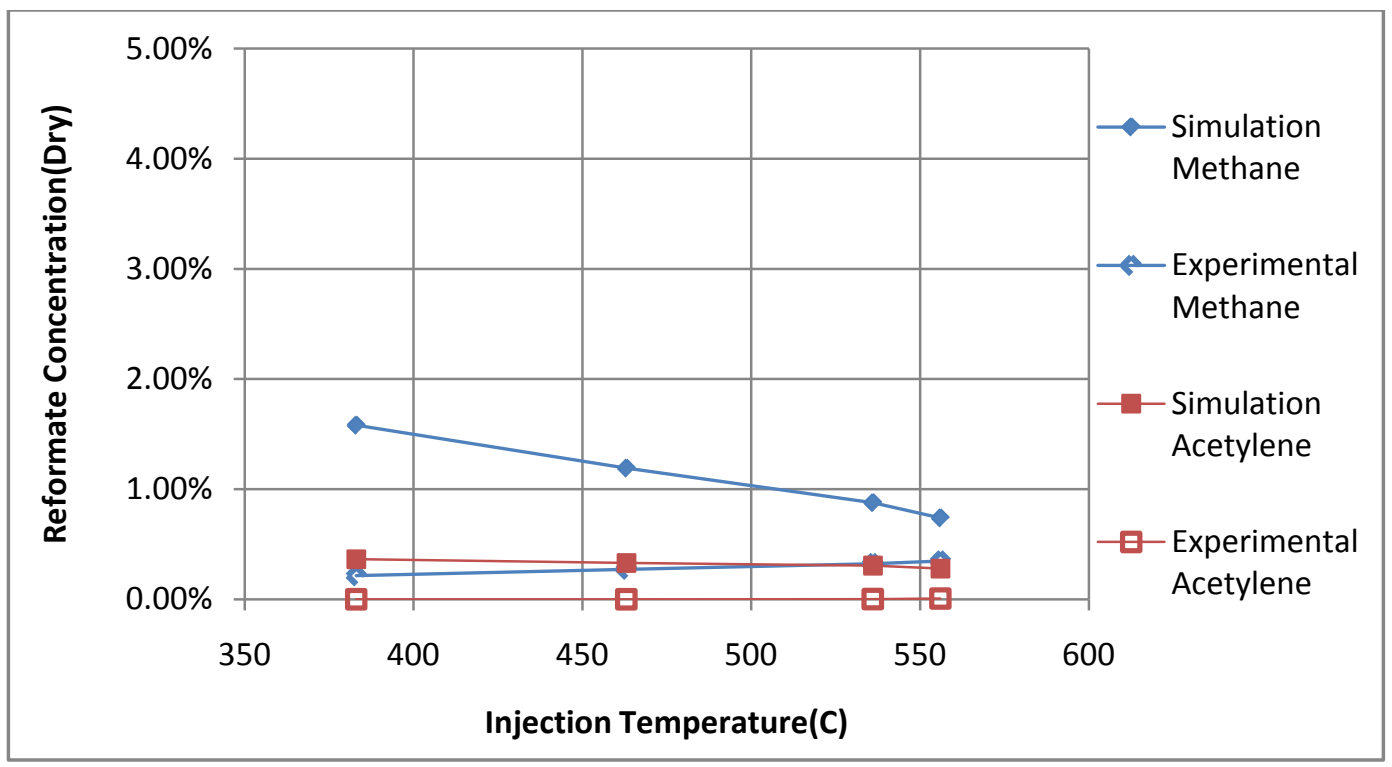

